\title{
Crescimento e produção de brócolis adubado com doses de mucuna-cinza em casa de vegetação
}

\section{Growth and yield of broccoli fertilized with doses of velvet bean in greenhouse}

\author{
Ellen Rúbia Dinizi ; Thiago de Oliveira Vargas ${ }^{2 *}$; Ricardo Henrique Silva Santos ${ }^{3}$; \\ Alysson Roberto de Almeida ${ }^{4}$; Urias João Batista Martins de Mattos ${ }^{4}$
}

\begin{abstract}
Resumo
Os efeitos de doses de adubos verdes na produção de olerícolas ainda são pouco conhecidos. São escassos os trabalhos científicos que indicam que o aumento da dose pode influenciar características das plantas. Os objetivos do trabalho foram avaliar o efeito de doses do adubo verde mucuna-cinza (Mucuna pruriens) no crescimento e produção, na partição da massa da matéria seca e do nitrogênio $(\mathrm{N})$ em plantas de brócolis (Brassica oleraceae var. italica), bem como determinar a recuperação aparente e a eficiência fisiológica do uso do N. Foram estabelecidos quatro tratamentos e uma testemunha absoluta. Os tratamentos consistiram de quatro doses de adubo verde: $0,3,6,9 \mathrm{tha}^{-1} \mathrm{em}$ base de matéria seca, com adição de $12 \mathrm{t} \mathrm{ha}^{-1}$ de composto orgânico. As doses de adubo verde aplicadas influenciaram o crescimento e a produtividade do brócolis. A distribuição da massa da matéria seca entre as partes da planta de brócolis não é influenciada pelas doses de adubo verde. As doses de adubo verde influenciaram positivamente a quantidade de $\mathrm{N}$ acumulada na inflorescência e na planta inteira do brócolis. A recuperação aparente do $\mathrm{N}$ do adubo verde e a eficiência do uso do $\mathrm{N}$ pelas plantas de brócolis estão associadas positivamente às doses aplicadas.
\end{abstract}

Palavras-chave: Mucuna pruriens, Brassica oleraceae var. italica, adubação verde, nitrogênio

\begin{abstract}
The dose effects of green manure in vegetable crops production are still poorly understood. There are few scientific studies indicate that increasing the dose may influence plants characteristics. The objectives were to evaluate the effect of doses of velvet bean green manure on growth and yield, the partitioning of dry matter and nitrogen $(\mathrm{N})$ in plants of broccoli, as well as determine the apparent recovery and physiological efficiency of use $\mathrm{N}$. We established four treatments plus a control. The treatments consisted of four levels of green manure: $0,3,6,9 \mathrm{t} \mathrm{ha}^{-1}$ on a dry matter basis, with the addition of $12 \mathrm{t} \mathrm{ha}^{-1}$ of compost. Doses of green manure applied influenced the growth and yield of broccoli. The distribution of dry matter between plant parts of broccoli is not influenced by the doses of green manure. Doses of green manure influenced the amount of $\mathrm{N}$ accumulated in the inflorescence and whole plant of broccoli. The apparent recovery of $\mathrm{N}$ from green manure and efficiency of $\mathrm{N}$ use by plants of broccoli are positively associated with the applied doses.
\end{abstract}

Key words: Mucuna pruriens, Brassica oleraceae var. italica, green manure, nitrogen

\footnotetext{
${ }_{1}$ Eng $^{\mathrm{a}}$ Agr $^{\mathrm{a}}$, Prof ${ }^{\mathrm{a}} \mathrm{Dr}^{\mathrm{a}}$, Instituto Federal de Educação, Ciência e Tecnologia do Paraná, Ivaiporã, PR. E-mail: ellen.diniz@ifpr.edu. br

2 Eng $^{\circ}$ Agr $^{\circ}$, Prof. Dr., Dept ${ }^{\circ}$ de Ciências Agrárias, Universidade Tecnológica Federal do Paraná, UTFPR. Pato Branco, PR. E-mail: thiagovargas@utfpr.edu.br

3 Eng $^{\circ}$ Agr $^{\circ}$, Prof. Dr., Dept ${ }^{\circ}$ de Fitotecnia, Universidade Federal de Viçosa, UFV, Viçosa, MG. E-mail: rsantos@ufv.br

4 Eng $^{\text {os }}$ Agr $^{\text {os }}$, Dept ${ }^{\circ}$ de Fitotecnia, UFV, Viçosa, MG. E-mail: alyssonra@yahoo.com.br; uriasmattos@hotmail.com

* Autor para correspondência
} 
Os efeitos de doses de adubos verdes na produção de olerícolas ainda são pouco conhecidos. São escassos os trabalhos científicos que demonstram o comportamento das plantas quando cultivadas com doses de adubos verdes.

Os adubos orgânicos indicam que o aumento da dose pode influenciar características das plantas como produção de alface (YURI et al., 2004); aumento do número de frutos de maracujá (DAMATTO JUNIOR et al., 2005) e resultaram em aumentos dos teores de nutrientes nos tecidos foliares diretamente proporcionais às doses, assim como aumento da massa total da parte aérea, produtividade, além da redução do ciclo da cultura do repolho (OLIVEIRA et al., 2003).

A compreensão dos processos envolvidos no fornecimento de $\mathrm{N}$ pelos adubos verdes são necessários estudos que estabeleçam uma relação entre as quantidades de $\mathrm{N}$ fornecidas e as extraídas pelas culturas. Para isso é fundamental uma estimativa do acúmulo de massa da matéria seca total e da quantidade de $\mathrm{N}$ requerida pela cultura principal, com a finalidade de poder avaliar a quantidade de massa do adubo verde fornecida (DINIZ et al., 2014). Atualmente essa estimativa é baseada em informações de plantas cultivadas com adubação mineral e sem a estimativa da massa da matéria seca da raiz da cultura principal.

Os objetivos do trabalho foram avaliar o efeito de doses do adubo verde mucuna-cinza (Mucuna pruriens) no crescimento, produção, partição da massa da matéria seca e do $\mathrm{N}$ em plantas de brócolis (Brassica oleracea var. italica) e avaliar a recuperação aparente e a eficiência fisiológica do uso do $\mathrm{N}$ derivado do adubo verde.

O trabalho foi realizado na área da Agroecologia do Departamento de Fitotecnia da Universidade Federal de Viçosa, em Viçosa - MG, localizada a $20^{\circ} 45^{\prime} 14^{\prime}$ ' S e $42^{\circ} 52^{\prime} 53^{\prime}$ ' W, a $650 \mathrm{~m}$ de altitude. $\mathrm{O}$ experimento foi instalado em casa de vegetação em vasos de 30 litros, com área superior de $0,15 \mathrm{~m}^{2}$, preenchido com 20 litros de substrato e uma planta de brócolis por vaso. O substrato foi composto de uma mistura solo: areia na proporção 1:1. O substrato foi adubado uniformemente para todos os tratamentos com $300 \mathrm{mg} \mathrm{dm}^{-3}$ de fósforo (P) na forma de superfosfato simples, $200 \mathrm{mg} \mathrm{dm}^{-3} \mathrm{de}$ FTE BR12 e $150 \mathrm{mg} \mathrm{dm}^{3}$ de potássio (K) na forma de cloreto de potássio. O P e o FTE BR12 foram aplicados durante o preparo do substrato. $\mathrm{O} \mathrm{K}$ foi parcelado em quatro vezes, aos $0,15,30$ e 60 dias após o transplante. A irrigação foi feita diariamente mantendo a capacidade de campo do solo com o recolhimento e devolução da água percolada ao vaso. Os resultados da análise química da amostra do substrato utilizado foram: $\mathrm{pH}_{(\mathrm{H} 2 \mathrm{O})}=6,6 ; \mathrm{P}_{\text {(Mehlich }}$ I) $=80,5 \mathrm{mg} \mathrm{dm}^{-3} ; \mathrm{K}_{(\text {Mehlich I) }}=11 \mathrm{mg} \mathrm{dm}{ }^{-3} ; \mathrm{Ca}^{2+}{ }_{(\mathrm{KCl}}$ ${ }_{1 \mathrm{M})}=1,0 \mathrm{cmol}_{\mathrm{c}} \mathrm{dm}^{-3} ; \mathrm{Mg}^{2+}{ }_{(\mathrm{KCl} 1 \mathrm{M})}=0,7 \mathrm{cmol}_{\mathrm{c}} \mathrm{dm}^{-3}$; $\mathrm{Al}^{3+}{ }_{(\mathrm{KCl} 1 \mathrm{M})}=0,0 \mathrm{cmol}_{\mathrm{c}} \mathrm{dm}^{-3} ; \mathrm{H}+\mathrm{Al}^{3+}=3,9 \mathrm{cmol}_{\mathrm{c}}$ $\mathrm{dm}^{-3} ; \mathrm{SB}=1,7 \mathrm{cmol}_{\mathrm{c}} \mathrm{dm}^{-3} ; \mathrm{CTC}(\mathrm{t})=1,7 \mathrm{cmol}_{\mathrm{c}} \mathrm{dm}^{-3}$; $\mathrm{CTC}(\mathrm{T})=5,7 \mathrm{cmol}_{\mathrm{c}} \mathrm{dm}^{-3} ; \mathrm{V}=30 \% ; \mathrm{m}=0 \%$.

Foram estabelecidos quatro tratamentos e uma testemunha absoluta. Os tratamentos consistiram de quatro doses de adubo verde: 0, 3, 6, $9 \mathrm{t} \mathrm{ha}^{-1} \mathrm{em}$ base de matéria seca, com adição de $12 \mathrm{t} \mathrm{ha}^{-1}$ de composto orgânico em base de matéria seca (DINIZ et al., 2008). Na testemunha absoluta não houve adição de composto orgânico.

O composto orgânico teve como material de origem capim elefante e cama de frango, numa proporção $3: 1$ (v/v). Os materiais foram compostados em pilhas com revolvimento manual. O composto orgânico foi misturado com $30 \%$ de umidade ao substrato, com FTE BR 12 e P momentos antes do transplantio das mudas, à exceção dos tratamentos testemunha absoluta. A composição química do composto orgânico utilizado foi de: $\mathrm{N}=1,48 \mathrm{dag}$ $\mathrm{kg}^{-1} ; \mathrm{P}=0,60$ dag kg-1$; \mathrm{K}=0,16$ dag $\mathrm{kg}^{-1} ; \mathrm{Ca}=1,61$ dag $\mathrm{kg}^{-1} ; \mathrm{Mg}=0,26$ dag $\mathrm{kg}^{-1} ; \mathrm{S}=0,50$ dag $\mathrm{kg}^{-1} ; \mathrm{MO}$ $=36,02 \mathrm{dag} \mathrm{kg}^{-1}$ e $\mathrm{C} / \mathrm{N}=15,25$.

O adubo verde utilizado foi a leguminosa mucuna-cinza produzida no campo e colhida aos 65 dias após o plantio, correspondendo a 20 dias antes do dia da aplicação nos vasos. O adubo verde depois 
de colhido foi secado na sombra e posteriormente armazenado em sacos de ráfia em galpão fechado. $\mathrm{O}$ plantio da leguminosa foi feita com inoculação das sementes com estirpe apropriada de Bradyrhizobium $s p$. As sementes foram plantadas na razão de 6 sementes por metro linear e $50 \mathrm{~cm}$ entre linhas. $\mathrm{O}$ adubo verde foi cortado ao nível do solo e amostras foram retiradas para determinar o teor de $\mathrm{N}$ pelo método Kjeldahl conforme Tedesco et al. (1995).

As amostras para análise foram secadas em estufa à $70^{\circ} \mathrm{C}$, até massa constante, em estufa de circulação forçada de ar. A análise química na matéria seca do adubo verde utilizado indicou os seguintes valores: $\mathrm{N}=2,21 \mathrm{dag}_{\mathrm{kg}^{-1}}$; polifenóis $=3,11 \mathrm{dag} \mathrm{kg}{ }^{-1}$; lignina $=$

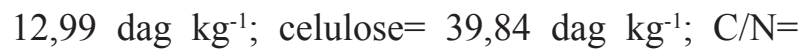
23,04; Lig/N=5,87; Pol/N=1,40 e Lig/Pol=0,32. O teor total de $\mathrm{N}$ foi determinado por Kjeldhal segundo Tedesco et al. (1995). O carbono total foi calculado a partir do teor de matéria orgânica total determinado pelo método da perda por ignição segundo Kiehl (1985). Os polifenóis foram extraídos com metanol $50 \%$ e determinados por colorimetria utilizando-se o reagente Folin-Denis (FRIGHETTO; VALARINI, 2000). Os teores de celulose e lignina foram obtidos via fibra detergente ácido a partir do material vegetal por ebulição com solução de ácido sulfúrico do brometo de cetiltrimetilamônio.

O adubo verde foi aplicado nos vasos em superfície no dia do transplantio do brócolis. Para o cálculo da quantidade aplicada em cada dose, em cada vaso, foi considerada a área ocupada por uma planta, $0,9 \times 0,5 \mathrm{~m}$, espaçamento recomendado para brócolis em campo. A correspondência da quantidade total de $\mathrm{N}$ aplicado via adubo verde nas doses 0, 3, 6 e $9 \mathrm{t} \mathrm{ha}^{-1}$ foram $0 ; 66,3 ; 132,6$ e 198,9 $\mathrm{kg}$ $\mathrm{ha}^{-1}$, sendo que ainda em cada dose foram aplicados $177,6 \mathrm{~kg} \mathrm{ha}^{-1}$ de $\mathrm{N}$ via composto orgânico. As doses adubo verde foram complementadas com composto orgânico, pois nem todo o $\mathrm{N}$ contido no adubo verde é mineralizado no período de demanda da cultura.

A decomposição da massa da mucuna-cinza foi avaliada pela diferença entre a perda de massa da matéria seca dos resíduos colocados sobre o substrato do vaso no momento do transplante e o resíduo final. Na colheita do brócolis, a massa da matéria seca de adubo verde remanescente em cada vaso foi recolhida e colocada para secar em estufa a $70^{\circ} \mathrm{C}$ seguindo de pesagem.

A recuperação aparente do $\mathrm{N}(\operatorname{REC} \mathrm{N}) \mathrm{da}$ adubação verde pelo brócolis foi calculada pela seguinte equação:

REC N (\%)= [Next AV - Next Test AB]. 100 / Qde de $\mathrm{N}$ aplicado.

Sendo, REC N (\%)= recuperação aparente do $\mathrm{N}$ pelo brócolis cultivado com adubação verde; Next AV $\left(\mathrm{kg} \mathrm{ha}^{-1}\right)=$ quantidade de $\mathrm{N}$ extraída pela massa total das plantas de brócolis cultivadas com as doses de adubo verde; Next Test $\mathrm{AB}\left(\mathrm{kg} \mathrm{ha}^{-1}\right)=$ quantidade de $\mathrm{N}$ extraída nas plantas de brócolis com a testemunha absoluta e Qde de $\mathrm{N}$ aplicado $(\mathrm{kg}$ ha $\left.^{-1}\right)=$ quantidade de $\mathrm{N}$ aplicado.

A eficiência fisiológica do uso do N (EFUN) derivado da adubação verde pelas plantas de brócolis, foi calculado segundo Fageria, Santos e Stone (2003) pela seguinte equação:

$\operatorname{EFUN}\left(\mathrm{g} \mathrm{g}^{-1}\right)=[\mathrm{MS} \mathrm{AV}]-[\mathrm{MS}$ Test AB $] /$

Qde de Ntotal acumulado na planta.

Sendo, EFUN $\left(\mathrm{g} \mathrm{g}^{-1}\right)=$ a eficiência fisiológica do uso do $\mathrm{N}$ derivado da adubação verde pelas plantas de brócolis; MS AV $(\mathrm{g})=$ produção de matéria seca do brócolis por planta em cada dose de adubo verde; MS Test $\mathrm{AB}(\mathrm{g})=$ produção de matéria seca por planta nas plantas cultivadas com a testemunha absoluta; Qde de Ntotal acumulado na planta $(\mathrm{g})=$ Quantidade total de N acumulado pela planta.

O semeio do brócolis (Brassica oleracea var. italica), híbrido de cabeça única 'Legacy', foi feito no dia 18/03/09 e as mudas transplantadas para os vasos no dia 11/04/09 e a colheita realizada no dia 13/07/09. O acúmulo de massa da matéria seca das plantas foi avaliado indiretamente pela altura e pela área do dossel, devido a uma alta correlação entre a área do dossel e altura e o acúmulo de massa da 
matéria seca das plantas (DINIZ et al., 2008). Foi realizada uma avaliação a cada 10 dias a partir do transplante (DAT) até 60 dias para a variável de crescimento área do dossel $\left(\mathrm{m}^{2}\right)$ calculada por duas medidas ortogonais da parte superior do dossel.

A produção do brócolis foi avaliada pela massa da matéria fresca da inflorescência colhida com $1,5 \mathrm{~cm}$ de pedúnculo floral. Na colheita a planta foi separada nas partes limbo foliar, pecíolo, caule, inflorescência e raiz. Após secagem em estufa a 70 ${ }^{\circ} \mathrm{C}$, até massa constante, as partes foram pesadas e foi determinado o teor de $\mathrm{N}$ pelo método Kjeldhal conforme Tedesco et al. (1995). A partir do teor de N se calculou o acúmulo de $\mathrm{N}$ nas partes e a proporção de $\mathrm{N}$ para cada parte em relação à planta inteira.

O índice de colheita (IC) foi calculado pela seguinte equação:

\section{IC $(\%)=$ (produção comercial). $100 /$ (MS total da planta).}

Sendo, a produção comercial= produção da matéria seca da inflorescência do brócolis e MS total da planta $=$ produção da matéria seca da planta inteira de brócolis.

A relação parte aérea: raízes foi calculada pela seguinte equação:

\section{$\mathrm{PA} / \mathrm{RA}=\mathrm{MS}$ da parte aérea da planta / MS da raiz da planta.}

Onde, a MS total da parte aérea $=$ Matéria seca total da parte aérea das plantas de brócolis em cada dose; MS da raiz da planta= Matéria seca da raiz da planta de brócolis em cada dose.

O delineamento experimental foi de blocos casualizados com quatro repetições no esquema de parcelas subdivididas no tempo para as variáveis de crescimento com ajuste dos modelos estatísticos pela metodologia de superfície de resposta. Os dados foram avaliados por meio de análise da variância (ANOVA) pelo teste $\mathrm{F}$ e regressão $(\mathrm{p} \leq 0,05)$.
A área do dossel cresceu linearmente com o aumento das doses de adubo verde (Figura 1). Devido à correlação positiva entre a área do dossel em plantas de brócolis e o acúmulo de matéria seca (DINIZ et al., 2007), demonstrando que o aumento da dose de adubo verde resulta em plantas de brócolis com maior acúmulo de matéria seca.

$\mathrm{O}$ adubo verde remanescente nos vasos, avaliado na colheita do brócolis, apresentou em média 2,5\% de $\mathrm{N}$ total. Este maior teor de $\mathrm{N}$ final pode ser explicado pela possível contaminação do resíduo de adubo verde remanescente pelo lixiviado que era constantemente retornado aos vasos. A massa da matéria seca remanescente era equivalente a 1,3 ; 2,6; e 3,9 tha ${ }^{-1}$, respectivamente nas doses de 3, 6 e $9 \mathrm{t} \mathrm{ha}^{-1}$. Neste caso foram mineralizados da massa do adubo verde durante o período de cultivo, nas respectivas doses de 3, 6 e $9 \mathrm{t} \mathrm{ha}^{-1}, 32,0 \mathrm{~kg} \mathrm{ha}^{-1} ; 64,0$ $\mathrm{kg} \mathrm{ha}^{-1} \mathrm{e} 96,0 \mathrm{~kg} \mathrm{ha}^{-1}$ de $\mathrm{N}$.

A redução da massa da matéria seca do adubo verde aos 90 dias após o transplante ocorreu na mesma proporção das doses. Houve mineralização, em média, de 57\% da quantidade inicial de massa adicionada no dia do transplante e uma mineralização, em média, de $51 \%$ da quantidade de $\mathrm{N}$ inicial em cada dose aplicada, embora a maior dose tivesse três vezes mais massa de adubo verde que a menor dose. Nesses cálculos não foram computados o $\mathrm{N}$ mineralizado do composto orgânico. Em outro estudo, aos 90 dias, a mineralização da massa da mucuna-cinza com uma relação $\mathrm{C} / \mathrm{N}$ de 30 foi de $37 \%$ da quantidade de $\mathrm{N}$ inicial (CARVALHO et al., 2008). Em ambos os experimentos as aplicações foram feitas em superfície, entretanto a relação $\mathrm{C} / \mathrm{N}$ encontrada na mucuna-cinca do presente trabalho foi igual a $23 \mathrm{e}$ essa menor relação $\mathrm{C} / \mathrm{N}$ possivelmente contribuiu para aumentar a velocidade da decomposição tanto da massa quanto da mineralização do N. 
Figura 1. Efeito de doses de adubo verde (D) e dias após o transplantio (T), sobre a área do dossel (AD) das plantas de brócolis.

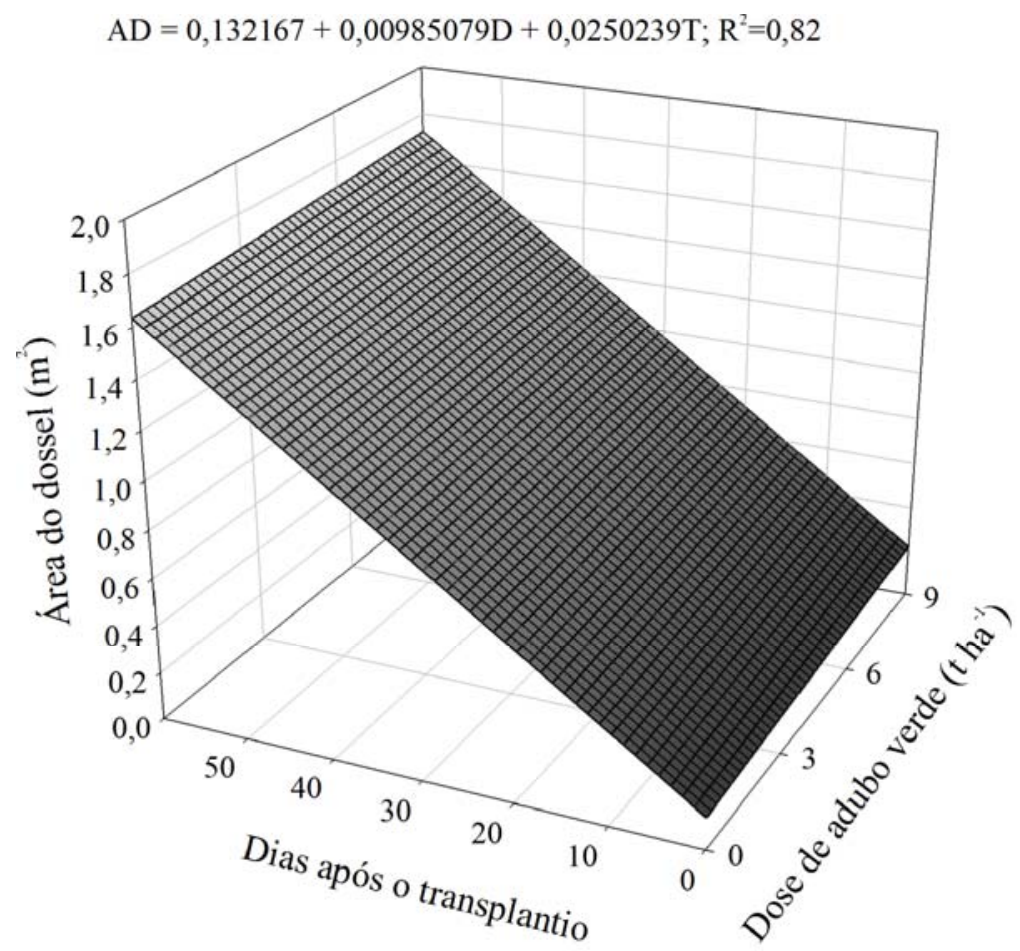

Fonte: Elaboração dos autores.

De acordo com Ribas et al. (2010), a mineralização do $\mathrm{N}$ dos resíduos de mucuna-cinza foi mais rápida do que a decomposição da massa, resultado diferente do encontrado no presente trabalho. Devido a mineralização incompleta do $\mathrm{N}$ do adubo verde e do $\mathrm{N}$ fornecido pelo composto orgânico, as doses de $\mathrm{N}$ estavam acima da quantidade recomendada para a produção do brócolis, $150 \mathrm{~kg}$ $\mathrm{ha}^{-1}$. Na dose $0 \mathrm{t} \mathrm{ha}^{-1}$ de adubo verde + composto orgânico foi aplicado $18 \%$ a mais de $\mathrm{N}$ do que a dose recomendada e na dose $9 \mathrm{t} \mathrm{ha}^{-1}$ de adubo verde + composto orgânico foi aplicado $151 \%$ a mais. Relatos de estudos com adubos verdes associados a outros adubos orgânicos, citam aplicações de quantidades de $\mathrm{N}$ superiores ao recomendado à cultura do brócolis. Foram utilizados $354,7 \mathrm{~kg} \mathrm{ha}^{-1}$ de $\mathrm{N}$ originados de $12 \mathrm{t} \mathrm{ha}^{-1}$ de composto orgânico conjuntamente a $8,6 \mathrm{t} \mathrm{ha}^{-1}$ de leguminosa por Diniz et al. (2007) e $36 \mathrm{t} \mathrm{ha}^{-1}$ de "cama" de aviário com adubação verde suplementar em pré-cultivo com Crotalaria juncea (4,5 t ha-1 equivalente a 116,32 $\mathrm{kg} \mathrm{ha}^{-1}$ de N) relatado por Oliveira et al. (2008). Maiores doses são usadas, possivelmente, porque nem todo o $\mathrm{N}$ contido no adubo verde ou composto orgânico pode ser mineralizado do material vegetal no período de demanda da cultura, como verificado no presente estudo. A disponibilidade do $\mathrm{N}$ do adubo verde para as plantas depende, além da quantidade aplicada, de outros fatores como a mineralização do N. Entretanto é importante considerar que o $\mathrm{N}$ residual poderá ser aproveitado em culturas subsequentes (VARGAS et al., 2013).

Em estudo sobre épocas de incorporação de adubo verde em brócolis orgânico utilizando mucuna-cinza, onde a dose aplicada do adubo verde foi $8,64 \mathrm{tha}^{-1}$ conjuntamente a $12 \mathrm{t} \mathrm{ha}^{-1}$ de composto orgânico, foi aplicado um total equivalente a 354,7 
$\mathrm{kg} \mathrm{ha}^{-1}$ de N (DINIZ et al., 2007), valor similar à quantidade aplicada no presente trabalho que foi de $347,1 \mathrm{~kg} \mathrm{ha}^{-1}$ de N. Nesse caso, a produção das plantas de brócolis foi similar à produção das plantas cultivadas com o $\mathrm{N}$ mineral (150 kg ha-1 de $\mathrm{N}$ ) ou com a aplicação de $25 \mathrm{t} \mathrm{ha}^{-1}$ de composto orgânico (370 kg ha-1 de N) (DINIZ et al., 2007).

O efeito das doses foi positivo em relação ao ganho de massa das partes da planta de brócolis, à exceção da raiz, que acumulou em média, 19,8 g de matéria seca independente da dose de adubo verde aplicada. Houve efeito linear das doses de adubo verde sobre a produção de matéria seca da planta inteira de brócolis e produção (Figura 2A), da matéria seca do limbo foliar, do caule, da inflorescência e do pecíolo (Figura 2B). O aumento das doses de adubo verde resultou em aumentos de massa de folhas e inflorescências. As plantas de brócolis acumularam $62 \%$ a mais de matéria seca total da planta inteira na maior dose em relação à menor dose e $126 \%$ a mais na inflorescência. Entretanto, o aumento da quantidade de $\mathrm{N}$ mineralizada, somente no adubo verde, na maior dose em relação à menor dose foi de $200 \%$.

A distribuição da matéria seca nas partes das plantas de brócolis em relação à massa da matéria seca total acumulada foi similar em todas as doses. Em média, as percentagens de matéria seca alocadas no limbo foliar, pecíolo, caule, inflorescência e raiz foram de $33,2 \% ; 11,2 \% ; 23,6 \% ; 18,8 \%$ e $13,2 \%$, respectivamente.

A produção de inflorescência de brócolis aumentou linearmente com o aumento das doses de adubo verde, alcançando 276,5 g por planta (Figura 2A). Essa mesma cultivar produzida a campo, em cultivo de verão em plantio direto, produziu 370,8 g por planta, sendo a adubação de base de 2,0 t ha ${ }^{-1}$ de cama de frango, $60 \mathrm{~kg} \mathrm{ha}^{-1}$ de $\mathrm{N}$ incorporados nas covas no plantio mais $200 \mathrm{~kg} \mathrm{ha}^{-1}$ de $\mathrm{N}$ mineral em coberturas parceladas em três vezes (MELO; MADEIRA; PEIXOTO, 2010). Esses resultados indicam a necessidade de maior compreensão e ajuste das doses de $\mathrm{N}$ aplicadas via adubação orgânica uma vez que as quantidades aplicadas são superiores às recomendadas.

Em condições de campo, de acordo com Diniz et al. (2007), a produção de brócolis foi de 600,39 $\mathrm{g}$ por planta em plantas cultivadas com $12 \mathrm{t} \mathrm{ha}^{-1}$ de composto orgânico conjuntamente a $8,6 \mathrm{t} \mathrm{ha}^{-1}$ de mucuna-cinza, num total de $354,7 \mathrm{~kg} \mathrm{ha}^{-1}$ de $\mathrm{N}$. Oliveira et al. (2003) avaliaram o crescimento e a produção de repolho com doses 12, 24 e $36 \mathrm{t} \mathrm{ha}^{-1} \mathrm{de}$ cama de aviário, com adubação verde suplementar em pré-cultivo com Crotalaria juncea e constataram aumentos diretamente proporcionais às doses tanto na massa total da parte aérea quanto no peso da cabeça e na produtividade, além de redução do ciclo da cultura. Entretanto, não há referência das quantidades totais de $\mathrm{N}$ adicionadas com a cama de aviário. Considerando o teor de $\mathrm{N}$ de 3,0\% na cama de aviário, conforme relatado por Oliveira et al. (2008) em trabalho subsequente, teriam sido fornecidos ao solo $1065,6 \mathrm{~kg} \mathrm{ha}^{-1}$ de $\mathrm{N}$ na maior dose somente com a cama de aviário. Comparando esses resultados aos do presente trabalho onde foi mineralizado $90,4 \mathrm{~kg}$ de $\mathrm{N}^{-1}$ com a maior dose de adubo verde mais a aplicação de $177,6 \mathrm{~kg}$ de $\mathrm{N}$ $\mathrm{ha}^{-1}$ com $12 \mathrm{t}$ ha ${ }^{-1}$ de composto orgânico totalizando $267,97 \mathrm{~kg}$ de $\mathrm{N} \mathrm{ha}^{-1}$, é possível inferir que a produção de brócolis pode ainda aumentar com doses maiores que $9 \mathrm{t} \mathrm{ha}^{-1}$ de adubo verde $+12 \mathrm{t} \mathrm{ha}^{-1}$ de composto. Esses resultados evidenciam possível aumento de produção das plantas de brócolis utilizando maiores doses composto e de adubo verde em condições de campo. 
Figura 2. Efeito de doses de adubo verde sobre a produção (PROD) e matéria seca da planta inteira (MSPI) (A); do pecíolo (MSPe), da inflorescência (MSIn), do caule (MSCa) e do limbo foliar (MSFo) (B); sobre a quantidade de $\mathrm{N}$ acumulado na inflorescência (QNIn) e planta inteira (QNPI) (C), e no teor de N-total na raiz (D) de plantas de brócolis.
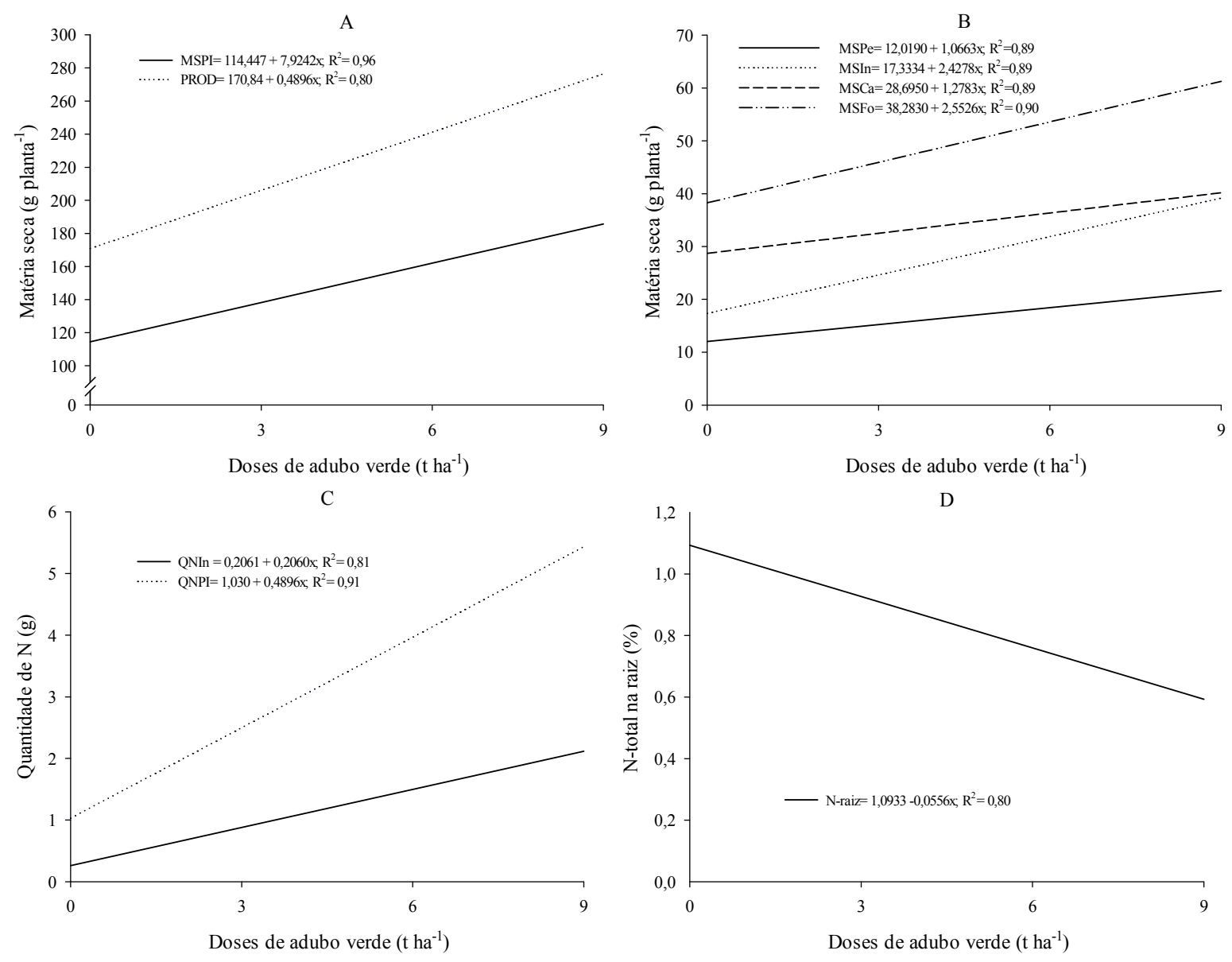

Fonte: Elaboração dos autores.

Houve efeito linear positivo de doses de adubo verde sobre a quantidade de $\mathrm{N}$ acumulada na inflorescência e na planta inteira (Figura 2C). Ao determinar o acúmulo e a exportação de nutrientes pela cultura da couve-flor 'Verona', em campo, Castoldi et al. (2009) verificaram que dos 28 aos 56 dias após o transplantio ocorreu a maior exigência por N. Neste caso, as folhas acumularam mais $\mathrm{N}$ do que o caule e o pecíolo, com acúmulo de 3,4; 0,3 e 1,1 g por planta, respectivamente. Já nas inflorescências, o acúmulo de $\mathrm{N}$ foi contínuo durante seu desenvolvimento, apresentando um acúmulo de 3,50 g de N por planta aos 69 dias. Considerando-

se a densidade plantada, 20.000 plantas por hectare, a exportação de $\mathrm{N}$ pela inflorescência foi de $70 \mathrm{~kg}$ ha $^{-1}$ e o total de $\mathrm{N}$ acumulado pela planta inteira aos 69 dias após o transplantio foi de 9,0 g, o que correspondeu a $183 \mathrm{~kg} \mathrm{ha}^{-1}$ de N (CASTOLDI et al., 2009).

No presente trabalho as folhas também acumularam maior quantidade de $\mathrm{N}$ em relação ao caule e ao pecíolo. $\mathrm{Na}$ maior dose de adubo verde houve acúmulo de 1,$3 ; 0,6$ e $0,2 \mathrm{~g}$ de $\mathrm{N}$ por planta, respectivamente. $\mathrm{O}$ acúmulo de $\mathrm{N}$ nas inflorescências das plantas que receberam a dose de 
$9 \mathrm{t} \mathrm{ha}^{-1}$ de adubo verde $+12 \mathrm{tha}^{-1}$ de composto foi de 1,2 g por planta aos 75 dias após o transplantio. Considerando o efeito de doses e a população de 22.222 plantas no campo, na maior dose de adubo verde houve um acúmulo total de $\mathrm{N}$ nas plantas de $100,20 \mathrm{~kg} \mathrm{ha}^{-1} \mathrm{e}$ uma exportação nas inflorescências de $45,8 \mathrm{~kg} \mathrm{ha}^{-1}$ de $\mathrm{N}$.

Não houve efeito das doses de adubo verde sobre a proporção de $\mathrm{N}$ alocada nas diferentes partes das plantas de brócolis em relação à planta inteira. Em média, as percentagens de $\mathrm{N}$ alocada no limbo foliar, pecíolo, caule, inflorescência e raiz foram de $38,7 \%$; $5,5 \% ; 15,3 \% ; 33,5 \%$ e $6,9 \%$, respectivamente.

À exceção da raiz, não houve efeito das doses de adubo verde sobre os teores de $\mathrm{N}$ nas demais partes da planta de brócolis. À medida que aumentou a dose de adubo verde diminuiu o teor de $\mathrm{N}$ nas raízes (Figura 2D). Em média, os teores de $\mathrm{N}$ nas partes das plantas que receberam as doses de adubo verde no limbo foliar, pecíolo, caule e inflorescência foram de $2,1 \% ; 0,8 \% ; 1,3 \%$ e $3,3 \%$, respectivamente.
Não houve efeito das doses de adubo verde sobre o índice de colheita das plantas de brócolis, que em média apresentou valor médio de 17,8\%. O índice de colheita expressa à eficiência da alocação da massa da matéria seca para as parte de valor econômico da planta e não mudou à medida que aumentou a dose de adubo verde aplicada.

Tanto a recuperação aparente do $\mathrm{N}$ como a eficiência fisiológica do uso do $\mathrm{N}$ do adubo verde mais composto orgânico foi maior nas plantas cultivadas com $9 \mathrm{t} \mathrm{ha}^{-1}$ de adubo verde $+12 \mathrm{t} \mathrm{ha}^{-1}$ de composto (Tabela 1). Esta maior recuperação aparente do $\mathrm{N}$ na maior dose aplicada possivelmente está relacionada com a maior disponibilidade do $\mathrm{N}$ no solo. Araújo et al. (2005) estudando a recuperação em plantas de trigo do $\mathrm{N}$ proveniente da ureia e da crotalária, constataram maior recuperação no solo do $\mathrm{N}$ derivado da crotalária $(85,1 \%)$ do que da uréia $(24,9 \%)$ e menor recuperação na planta de trigo do $\mathrm{N}$ derivado da crotalária (8\%) que derivado da uréia (61\%).

Tabela 1. Recuperação aparente do $\mathrm{N}(\operatorname{Rec} \mathrm{N})$ e eficiência fisiológica de utilização do N (EFUN) das plantas de brócolis cultivadas com dose $0 \mathrm{t} \mathrm{ha}^{-1}$ de adubo verde $+12 \mathrm{t} \mathrm{ha}^{-1}$ de composto $(0 \mathrm{AV}+12 \mathrm{CP})$; dose $3 \mathrm{t} \mathrm{ha}^{-1}$ de adubo verde $+12 \mathrm{t} \mathrm{ha}^{-1}$ de composto $(3 \mathrm{AV}+12 \mathrm{CP})$; dose $6 \mathrm{tha}^{-1}$ de adubo verde $+12 \mathrm{tha}^{-1}$ de composto $(6 \mathrm{AV}+12 \mathrm{CP})$; dose $9 \mathrm{t} \mathrm{ha}^{-1}$ de adubo verde $+12 \mathrm{t} \mathrm{ha}^{-1}$ de composto $(9 \mathrm{AV}+12 \mathrm{CP})$.

\begin{tabular}{lcc}
\hline Tratamentos & Rec N $(\%)$ & EFUN $\left(\mathrm{g} \mathrm{g}^{-1}\right)$ \\
\hdashline $0 \mathrm{AV}+12 \mathrm{CP}$ & $-6,51$ & 0,96 \\
$3 \mathrm{AV}+12 \mathrm{CP}$ & 4,56 & 13,96 \\
$6 \mathrm{AV}+12 \mathrm{CP}$ & 5,89 & 17,93 \\
$9 \mathrm{AV}+12 \mathrm{CP}$ & 8,45 & 21,99 \\
\hline
\end{tabular}

Fonte: Elaboração dos autores.

A eficiência de recuperação do $\mathrm{N}$ da adubação verde isoladamente, utilizando a dose $0 \mathrm{t} \mathrm{ha}^{-1} \mathrm{de}$ adubo verde como testemunha, aumenta para 10,$7 ; 10,6$ e $12,6 \%$ a recuperação do $\mathrm{N}$ na planta derivado do adubo verde nas doses 3,6 e $9 \mathrm{t} \mathrm{ha}^{-1}$, respectivamente. Dessa forma, a recuperação do $\mathrm{N}$ do adubo verde é maior do que a recuperação do $\mathrm{N}$ do composto, possivelmente, porque o $\mathrm{N}$ do adubo verde está numa forma mais disponível do que o $\mathrm{N}$ derivado do composto orgânico.
A maior recuperação aparente do $\mathrm{N}$ foi em plantas cultivadas com $9 \mathrm{t} \mathrm{ha}^{-1}$ de adubos verde +12 $\mathrm{t}$ ha ${ }^{-1}$ de composto, as quais também apresentaram eficiência fisiológica 1,6 vezes maior que a eficiência fisiológica apresentada pelas plantas cultivadas com $3 \mathrm{t} \mathrm{ha}^{-1}$ de adubos verde $+12 \mathrm{t} \mathrm{ha}^{-1}$ de composto. $\mathrm{O}$ acúmulo de massa nas plantas cultivadas com $9 \mathrm{t}$ $\mathrm{ha}^{-1}$ de adubo verde $+12 \mathrm{t} \mathrm{ha}^{-1}$ de composto ocorreu com uma maior eficiência fisiológica no uso do $\mathrm{N}$ do que nas plantas cultivadas com doses menores. 
Não houve efeito dos tratamentos e nem das doses de adubo verde na relação parte aérea: raízes das plantas. Independente do tratamento as plantas não alteraram o equilíbrio entre raízes e parte aérea. Em média a relação parte aérea: raízes foi de 6,62.

As doses de adubo verde influenciam positivamente o crescimento e a produtividade do brócolis. A distribuição da massa da matéria seca entre as partes da planta de brócolis não é influenciada pelas doses de adubo verde. As doses de adubo verde influenciam positivamente a quantidade de $\mathrm{N}$ acumulada na inflorescência e na planta inteira do brócolis. A recuperação aparente do $\mathrm{N}$ do adubo verde e a eficiência do uso do $\mathrm{N}$ pelas plantas de brócolis estão associadas positivamente as doses aplicadas.

\section{Agradecimentos}

Ao $\mathrm{CNPq}$ pelo apoio financeiro a pesquisa.

\section{Referências}

ARAÚJO, A. S. F.; TEIXEIRA, G. M.; CAMPOS, A. X.; SILVA, F. C.; AMBROSANO, E. J.; TRIVELIN, P. C. O. Utilização de nitrogênio pelo trigo cultivado em solo fertilizado com adubo verde (Crotalaria juncea) e/ ou uréia. Ciência Rural, Santa Maria, v. 35, n. 2, p. 284289, 2005.

CARVALHO, A. M.; BUSTAMANTE, M. M. C.; SOUSA, J. J. G. A.; VIVALDI, L. J. Decomposição de resíduos vegetais em latossolo sob cultivo de milho e plantas de cobertura. Revista Brasileira de Ciência do Solo, Viçosa, v. 32, p. 2831-2838, 2008. Número Especial.

CASTOLDI, R.; CHARLO, H. C. O.; VARGAS, P. F.; BRAZ, L. T. Crescimento, acúmulo de nutrientes e produtividade da cultura da couve-flor. Horticultura Brasileira, Brasília, v. 27, n. 4, p. 438-446, 2009.

DAMATTO JUNIOR, E. R.; LEONEL, S.; PEDROSO, C. J. Adubação orgânica na produção e qualidade de frutos de maracujá-doce. Revista Brasileira de Fruticultura, Jaboticabal, v. 27, n. 1, p. 188-190, 2005.
DINIZ, E. R.; SANTOS, R. H. S.; URQUIAGA, S. S.; PETERNELLI, L. A.; BARRELLA, T. P.; FREITAS, G. B. Green manure incorporation timing for organically grown broccoli. Pesquisa Agropecuária Brasileira, Brasília, v. 42, n. 2, p. 199-206, 2007.

Crescimento e produção de brócolis em sistema orgânico em função de doses de composto. Ciência e Agrotecnologia, Lavras, v. 32, n. 5, p. 1428-1434, 2008.

DINIZ, E. R.; VARGAS, T. O.; PEREIRA, W. D.; GUEDES, A. F.; SANTOS, R. H. S.; PETERNELLI, L. A. Decomposition and mineralization of the nitrogen from the green manure Crotalaria juncea. Cientifica, Jaboticabal, v. 42, n. 1, p. 51-59, 2014.

FAGERIA, N. K.; SANTOS, A. B.; STONE, L. F. Manejo de nitrogênio em arroz irrigado. Santo Antônio de Goiás: Embrapa Arroz e Feijão, 2003. 4 p. (Circular técnica, 58).

FRIGHETTO, R. T. S.; VALARINI, P. J. (Coord.). Indicadores biológicos e bioquímicos da qualidade do solo: manual técnico. Jaguariúna: Embrapa Meio Ambiente, 2000. 198 p. (Embrapa Meio Ambiente. Documentos, 21).

KIEHL, J. B. Fertilizantes orgânicos. São Paulo: Ed. Agron. Ceres, 1985. 492 p.

MELO, R. A. C.; MADEIRA, N. R.; PEIXOTO, J. R. Cultivo de brócolos de inflorescência única no verão em plantio direto. Horticultura Brasileira, Brasília, v. 28, n. 1, p. 23-28, 2010.

OLIVEIRA, F. L.; GUERRA, J. G. M.; ALMEIDA, D. L.; RIBEIRO, R. L. D.; SILVA, E. E.; SILVA, V. V.; ESPINDOLA, J. A. Desempenho de taro em função de doses de cama de aviário, sob sistema orgânico de produção. Horticultura Brasileira, Brasília, v. 26, n. 2, p. 149-153, 2008.

OLIVEIRA, F. L.; RIBAS, R. G. T.; JUNQUEIRA, R. M.; PADOVAN, M. P.; GUERRA, J. G. M.; ALMEIDA, D. L.; RIBEIRO, R. L. D. Uso do pré-cultivo de Crotalaria juncea e de doses crescentes de "cama" de aviário na produção do repolho sob manejo orgânico. Agronomia, Seropédica, v. 37, n. 2, p. 60-66, 2003.

RIBAS, R. G. T.; SANTOS, R. H. S.; SIQUEIRA, R. G.; DINIZ, E. R.; PETERNELLI, L. A.; FREITAS, G. B. Decomposição, liberação e volatilização de nitrogênio em resíduos culturais de mucuna-cinza (Mucuna cinerea). Ciência e Agrotecnologia, Lavras, v. 34, n. 4, p. 878-885, 2010.

TEDESCO, M. J.; GIANELLO, C.; BISSANI, C. A.; BOHNEN, H.; VOLKEISS, S. J. Análise de solo, plantas e outros materiais. Porto Alegre: Departamento de Solo, Faculdade de Agronomia, Universidade Federal do Rio Grande do Sul, 1995. 174 p. 
YURI, J. E.; RESENDE, G. M.; RODRIGUES JÚNIOR, J. C.; MOTA, J. H.; SOUZA, R. J. Efeito de composto orgânico sobre a produção e características comerciais de alface americana. Horticultura Brasileira, Brasília, v. 22, n. 1, p. 127-130, 2004.
VARGAS, T. O.; DINIZ, E. R.; SANTOS, R. H. S.; URQUIAGA, S.; CECON, P. R. Nitrogen contributions of legume roots to cabbage nutrition. Scientia Agricola, Piracicaba, v. 70, n. 6, p. 415-421, 2013. 